\title{
Extracorporeal Membrane Oxygenation for Coronavirus Disease 2019: Expert Recommendations from The Korean Society for Thoracic and Cardiovascular Surgery
}

\author{
In Seok Jeong, M.D. ', Woong-Han Kim, M.D. ${ }^{2}$, Jong Hyun Baek, M.D. ${ }^{3}$, Chang-Hyu Choi, M.D. , Chang Woo Choi, M.D. ${ }^{5}$, \\ Euy Suk Chung, M.D. ${ }^{6}$, Jae Seok Jang, M.D. , Woo Sung Jang, M.D. ${ }^{8}$, Hanna Jung, M.D. ${ }^{9}$, Jae-Seung Jung, M.D. ${ }^{10}$, \\ Pil Je Kang, M.D. ${ }^{11}$, Dong Jung Kim, M.D. ${ }^{12}$, Do Wan Kim, M.D. ${ }^{1}$, Hyoung Soo Kim, M.D. ${ }^{13}$, Jae Bum Kim, M.D. ${ }^{8}$, \\ Woo-Shik Kim, M.D. ${ }^{14}$, Young Sam Kim, M.D. ${ }^{15}$, Jae Gun Kwak, M.D. ${ }^{2}$, Haeyoung Lee, M.D. ${ }^{16}$, Seok In Lee, M.D. ${ }^{4}$, \\ Jae Woong Lim, M.D. ${ }^{5}$, Se Jin Oh, M.D. ${ }^{17}$, Tak-Hyuck Oh, M.D. ${ }^{9}$, Chun Soo Park, M.D. ${ }^{18}$, Kyoung Min Ryu, M.D. ${ }^{19}$, \\ Man-Shik Shim, M.D. ${ }^{20}$, Joohyung Son, M.D. ${ }^{21}$, Kuk Hui Son, M.D. ${ }^{4}$, Seunghwan Song, M.D. ${ }^{22}$, on behalf of The \\ Korean Society for Thoracic and Cardiovascular Surgery COVID-19 ECMO Task Force Team
}

\begin{abstract}
'Department of Thoracic and Cardiovascular Surgery, Chonnam National University Hospital, Chonnam National University Medical School, Gwangju; ${ }^{2}$ Department of Thoracic and Cardiovascular Surgery, Seoul National University Children's Hospital, Seoul National University College of Medicine, Seoul; ${ }^{3}$ Department of Thoracic and Cardiovascular Surgery, Yeungnam University Medical Center, Yeungnam University College of Medicine, Daegu; Department of Thoracic and Cardiovascular Surgery, Gachon University Gil Medical Center, Gachon University College of Medicine, Incheon; Department of Thoracic and Cardiovascular Surgery, Soonchunhyang University Bucheon Hospital, Soonchunhyang University College of Medicine, Bucheon; ${ }^{6}$ Department of Thoracic and Cardiovascular Surgery, Inje University Sanggye Paik Hospital, Inje University College of Medicine, Seoul; ${ }^{7}$ Department of Thoracic and Cardiovascular Surgery, Daegu Catholic University Medical Center, Daegu Catholic University School of Medicine; ${ }^{8}$ Department of Thoracic and Cardiovascular Surgery, Keimyung University Dongsan Hospital, Keimyung University School of Medicine; ${ }^{9}$ Department of Thoracic and Cardiovascular Surgery, Kyungpook National University Hospital, Kyungpook National University School of Medicine, Daegu; ${ }^{10}$ Department of Thoracic and Cardiovascular Surgery, Korea University College of Medicine; ${ }^{11}$ Department of Thoracic and Cardiovascular Surgery, Asan Medical Center, University of Ulsan College of Medicine, Seoul; ${ }^{12}$ Department of Thoracic and Cardiovascular Surgery, Seoul National University Bundang Hospital, Seoul National University College of Medicine, Seongnam; ${ }^{13}$ Department of Thoracic and Cardiovascular Surgery, Hallym Sacred Heart Hospital, Hallym University College of Medicine, Chuncheon; ${ }^{14}$ Department of Thoracic and Cardiovascular Surgery, National Medical Center, Seoul; ${ }^{15}$ Department of Thoracic and Cardiovascular Surgery, Inha University Hospital, Inha University School of Medicine, Incheon; ${ }^{16}$ Department of Thoracic and Cardiovascular Surgery, Kosin University Gospel Hospital, Kosin University College of Medicine, Busan; ${ }^{17}$ Department of Thoracic and Cardiovascular Surgery, SMG-SNU Boramae Medical Center, Seoul National University College of Medicine; ${ }^{18}$ Division of Pediatric Cardiac Surgery, Asan Medical Center, University of Ulsan College of Medicine, Seoul; ${ }^{19}$ Department of Thoracic and Cardiovascular Surgery, Dankook University Hospital, Cheonan; ${ }^{20}$ Department of Thoracic and Cardiovascular Surgery, Chungnam National University Hospital, Chungnam National University College of Medicine, Daejeon; ${ }^{21}$ Department of Thoracic and Cardiovascular Surgery, Pusan National University Yangsan Hospital, Yangsan; ${ }^{22}$ Department of Thoracic and Cardiovascular Surgery, Pusan National University Hospital, Pusan National University School of Medicine, Busan, Korea
\end{abstract}

\section{ARTICLE INFO}

Received January 4, 2021

Accepted January 8, 2021

Corresponding author

Woong-Han Kim

Tel 82-2-2072-3637

Fax 82-2-764-3664

E-mail woonghan@snu.ac.kr

ORCID

https://orcid.org/0000-0003-2837-7929
Since the first reported case of coronavirus disease 2019 (COVID-19) in December 2019, the numbers of confirmed cases and deaths have continued to increase exponentially despite multi-factorial efforts. Although various attempts have been made to improve the level of evidence for extracorporeal membrane oxygenation (ECMO) treatment over the past 10 years, most experts still hesitate to take an active position on whether to apply ECMO in COVID-19 patients. Several ECMO management guidelines have been published recently, but they reflect some important differences from the Korean medical system and aspects of real-world medical practice in Korea. We aimed to find evidence on the efficacy of ECMO for COVID-19 patients by reviewing the published literature and to propose expert recommendations by analyzing the Korean COVID-19 ECMO registry data.

Keywords: Extracorporeal membrane oxygenation, COVID-19, Pandemics, Acute respiratory distress syndrome, Cardiogenic shock 


\section{Introduction}

Within 1 year after the first reported case of coronavirus disease 2019 (COVID-19) in December 2019, in Wuhan, China, over 80,000,000 confirmed cases and about 2,000,000 deaths have been reported, and these numbers continue to increase exponentially despite massive efforts to combat the disease [1]. In South Korea (hereafter, Korea), the third wave of COVID-19 hit in November 2020. As of December 31,2020 , approximately 60,000 confirmed cases and 900 deaths have been reported. Since the cumulative number of critically ill patients is also gradually increasing, the lack of intensive care unit (ICU) beds and advanced facilities is emerging as an issue in Korea [2].

The application of extracorporeal membrane oxygenation (ECMO) to patients with severe acute respiratory distress syndrome (ARDS) is a promising modality to correct refractory hypoxia or hypercapnia and to prevent lung injury from prolonged mechanical ventilation (MV). However, ECMO also has many complications, both indirect and direct, including those that result from the contact of blood with artificial surfaces, such as additional inflammatory cascades, bleeding, and thrombosis [3]. If ECMO is started after irreversible organ damage has already occurred, it is impossible to achieve optimal oxygen uptake and consumption at the cellular level even if ECMO delivers sufficient oxygen through the blood. For this reason, the timing of ECMO application is critically important for patients' recovery and ECMO should be applied before irreversible damage occurs.

According to an international multicenter survey conducted in early 2020 after the onset of the COVID-19 pandemic, physicians' confidence in the pandemic era was closely related to the preparedness of ECMO facilities [4]. Therefore, we aimed to find evidence for the efficacy of ECMO in COVID-19 patients by reviewing the published literature and to propose expert recommendations by analyzing the Korean COVID-19 ECMO registry data.

\section{Lessons learned from CESAR and EOLIA trials, including the $\mathrm{H} 1 \mathrm{~N} 1$ and MERS outbreaks}

\section{CESAR trial and H1N1 outbreak}

The first relevant randomized clinical trial, known as the Conventional Ventilatory Support Versus Extracorporeal Membrane Oxygenation for Severe Adult Respiratory Failure (CESAR) Study, demonstrated the efficacy of venovenous (VV) ECMO for severe ARDS in 2009 in the United Kingdom, which eventually led to significant survival benefits from ECMO during the H1N1 influenza pandemic. The authors recommended transferring adult patients with severe but reversible respiratory failure (Murray score $>3$ or $\mathrm{pH}<7.2$ under optimal conventional management) to an ECMO center [5]. In Europe, Australia, and some other countries, multicenter ECMO results during the H1N1 pandemic have been reported. The standard features of these results are that ECMO was applied in selected patients with an average age of 30-40 years and the MV period was shorter than 5 days before the start of ECMO; additionally, national or regional ECMO referral systems were well established in these countries. The reported survival rate of these studies was $50 \%-80 \%$, which was relatively high [6-12].

\section{MERS outbreak}

The 2012-2015 outbreak of Middle East respiratory syndrome (MERS), which is caused by a novel coronavirus (MERS-CoV), was not a pandemic; instead, the outbreak mainly occurred in Saudi Arabia and Korea. Moreover, the reproductive number of MERS-CoV was not higher than that of other infectious diseases, and hospital-acquired infection, not community-acquired infection, was the leading route of transmission [13]. Alshahrani et al. [14] reported a multicenter experience of 17 MERS patients who received ECMO. The ECMO group showed lower mortality than MERS patients who received conventional treatment [14]. In Korea, although ECMO became known to the public after the MERS outbreak in 2015, very limited data have been published on MERS patients who received ECMO [15].

\section{EOLIA trial and following studies}

Combes et al. [16] conducted an international and randomized control trial, called the ECMO to Rescue Lung Injury in Severe ARDS (EOLIA) trial, to prove the effectiveness of ECMO treatment in severe ARDS patients, and reported the results in 2018. The EOLIA trial is recognized as the most meaningful ARDS-related ECMO study to date. The authors randomized patients with severe ARDS into a control group (conventional treatment with ECMO backup) and an early ECMO group based on the $\mathrm{PaO}_{2} / \mathrm{FiO}_{2}$ (PF) ratio (less than $50 \mathrm{~mm} \mathrm{Hg}$ for 3 hours or less than 80 $\mathrm{mm} \mathrm{Hg}$ for 6 hours). The 60 -day mortality rate was compared. For the control group, crossover to ECMO was al- 
lowed in case of refractory hypoxemia. Although there was no statistically significant survival benefit in the early ECMO group, the final result showed the meaningful finding that the late ECMO application in the crossover group resulted in a poor outcome [16].

Moreover, through the results of subsequent statistical verification (post hoc Bayesian analysis), it was possible to infer optimism about the effectiveness of ECMO application [17]. Two following papers presenting meta-analyses of the CESAR and EOLIA studies $[18,19]$, which were published in 2019 and 2020, showed additional evidence that ECMO should be regarded as an essential modality in severe ARDS when patients do not respond to conventional treatment. The EOLIA study results have been a cornerstone for suggesting that ECMO treatment may be effective in COVID-19 patients with ARDS who do not respond to conventional treatment.

\section{Evidence of ECMO in patients with COVID-19}

\section{WHO COVID-19 guidelines and others}

To date, the World Health Organization (WHO) has published clinical guidelines related to COVID-19 in March 2020 [20] and May 2020 [21]. The National Institutes of Health regularly update a guideline [22], and the Survival Sepsis Campaign study group also introduced a COVID-19 guideline [23]. None of these three guidelines take an active position on whether to apply ECMO in COVID-19 patients. However, with a weak recommendation, a standard proposal is made that ECMO treatment can be applied in carefully selected COVID-19 patients, based on the previously introduced EOLIA study results.

\section{ELSO COVID-19 guideline}

The Extracorporeal Life Support Organization (ELSO) has published guidelines related to ECMO twice in March 2020 [24] and July 2020 [25], constituting the most indepth set of guidelines for ECMO in COVID-19 patients to date. In the interim guideline released in July, detailed explanations are provided with a classification into 11 detailed items, such as organization, patient selection, timing of ECMO initiation, cannulation strategies, ongoing care, weaning, decannulation, transport on ECMO, and ethical dilemmas. It is suggested that the standard for applying VV ECMO should not be different from the standard for applying ECMO in patients with existing ARDS. VA
ECMO should be applied before multiple organ failure occurs, and the possibility should be considered that COVID-19 infection is positively correlated with hypercoagulability. According to the ELSO guideline, older age ( $\geq 65$ years), obesity (body mass index $\geq 40 \mathrm{~kg} / \mathrm{m}^{2}$ ), and immunocompromised status are relative contraindications, while advanced age, clinical frailty scale category $\geq 3$, MV for $>10$ days, and ongoing cardiopulmonary resuscitation are regarded as absolute contraindications. Finally, strict ECMO application criteria should be prepared if the hospital's capacity for patients is exceeded.

\section{Difference between COVID-19-related ARDS and non-COVID-19-related ARDS}

As severe acute respiratory syndrome coronavirus 2 (SARS-CoV-2) has various genetic modifications and is classified into various phenotypes, concerns have been raised regarding the possibility of differences in the clinical course according to the patient's genetic factors and virus phenotype. However, clinicians' primary concern is the difference between COVID-19-related ARDS (COVID ARDS) and classical ARDS (or non-COVID-19-related ARDS), as well as the various phenotypes of SARS-CoV-2. The differences between COVID ARDS and classical ARDS that have been commonly mentioned in several studies, are decreased lung compliance and a high possibility of progression to severe ARDS in COVID ARDS patients. The authors of those studies asserted that even though various COVID-19 patients show a progression of the atypical pattern during the treatment process, it is preferable to continue usual treatment strategies, such as applying lung-protective ventilation, prone positioning, and maintaining optimal positive end expiratory pressure [2628].

\section{Cardiovascular involvement of COVID-19 infections}

It was reported that severe inflammation and cardiovascular involvement developed in up to $25 \%$ of patients with COVID-19 [29]. Initially, the main mechanism of cardiac involvement was thought to be direct invasion of SARSCoV-2 into the myocardium through the angiotensin 2 receptor [30]. Recently, more diverse mechanisms of myocardial involvement have been suggested, such as hypoxia, microvascular damage, and systemic inflammation [31]. Therefore, when advanced cardiogenic shock is suspected in COVID-19 patients, VA ECMO should be actively con- 
sidered from the initial stage.

\section{Recent report from ELSO registry data}

During the early period of the COVID-19 pandemic, there were many concerns about the feasibility and effectiveness of ECMO, and the initial reports from China in March were somewhat disappointing [32,33]. Based on the ELSO COVID-19 registry with 1,000 patients' data (published online in September 2020), in-hospital mortality was reported to be around $37 \%$, reflecting a significant improvement compared to the initial reports in March 2020, comparable to the recent ELSO report on VV ECMO in patients with classical ARDS [34]. The risk factors of mortality were similar to what is generally known. First, age was reported to be the risk factor that was most closely related to mortality. In addition, a low PF ratio when starting ECMO, acute kidney injury, chronic respiratory failure, immunocompromised status, and cardiac arrest before starting ECMO were also reported to be risk factors for mortality.

\section{Expert recommendations based on the Korean COVID-19 ECMO registry}

From February 21 to October 31, 2020, we collected clinical data from 61 COVID-19 ECMO patients at 21 centers to establish a Korean COVID-19 ECMO registry. The data of this registry were analyzed to generate recommendations for COVID-19 ECMO patients (Table 1).

\section{Establishment of an ECMO management system at each individual ECMO center}

Decisions on ECMO application and patient management should be made through a multidisciplinary team

Table 1. Expert recommendations based on the Korean COVID-19 ECMO registry

\begin{tabular}{|c|c|}
\hline & Recommendations \\
\hline $\begin{array}{l}\text { 1. Establishment of an ECMO } \\
\text { management system at each } \\
\text { individual ECMO center }\end{array}$ & $\begin{array}{l}\text { 1.1. Multidisciplinary ECMO team approach: Decisions on ECMO application and patient } \\
\text { management should be made through a multidisciplinary team approach, including a } \\
\text { cardiothoracic surgeon. } \\
\text { 1.2. Referral and retrieval system: It is recommended that each ECMO center should prepare a } \\
\text { referral and retrieval system in consideration of its capacity. }\end{array}$ \\
\hline $\begin{array}{l}\text { 2. Establishment of criteria for } \\
\text { patient selection }\end{array}$ & $\begin{array}{l}\text { 2.1. Early alert criteria: ECMO application may be considered if hypoxia (e.g., a PF ratio less than } \\
150 \mathrm{~mm} \mathrm{Hg} \text { ) or cardiogenic shock (e.g., hypotension, elevated lactate, or metabolic acidosis) } \\
\text { persists after appropriate treatment in COVID-19 patients. If the patient's condition is likely to } \\
\text { deteriorate in hospitals without ECMO facilities, it is necessary to consider prompt transfer to an } \\
\text { ECMO center. } \\
\text { 2.2. COVID-19 patients with ARDS: In patients with ARDS, VV ECMO is recommended if the PF } \\
\text { ratio is less than } 50 \mathrm{~mm} \mathrm{Hg} \text { for more than } 3 \text { hours or less than } 80 \mathrm{~mm} \mathrm{Hg} \text { for more than } 6 \text { hours, } \\
\text { based on World Health Organization guidelines. If the condition does not improve even after } \\
\text { conventional management with optimal intensive care unit care (e.g., mechanical ventilation, } \\
\text { prone positioning), ECMO is recommended within } 5 \text { days after the initiation of invasive } \\
\text { mechanical ventilation. } \\
\text { 2.3. COVID-19 patients with cardiogenic shock: Prompt ECMO application is recommended } \\
\text { in patients with advanced cardiogenic shock if appropriate medical treatments fail to yield } \\
\text { improvements. If cardiogenic shock develops in a patient undergoing VV ECMO, transition to } \\
\text { venoarterial or hybrid ECMO should be considered promptly. } \\
\text { 2.4. Co-morbidities and other pre-ECMO conditions: An analysis of the Korean COVID-19 ECMO } \\
\text { registry showed that diabetes and mechanical ventilation for more than } 7 \text { days are significant risk } \\
\text { factors for mortality. We recommend a careful decision on ECMO application in such patients. }\end{array}$ \\
\hline $\begin{array}{l}\text { 3. Stringent triage and allocation } \\
\text { criteria of limited resource in } \\
\text { a persistent pandemic era }\end{array}$ & $\begin{array}{l}\text { If the COVID-19 outbreak continues and the shortage of medical and personnel resources (including } \\
\text { ECMO facilities) worsens, we recommend that more strict criteria should be applied for patient } \\
\text { selection. }\end{array}$ \\
\hline $\begin{array}{l}\text { 4. Futility and ethical issues of } \\
\text { life-sustaining treatment }\end{array}$ & $\begin{array}{l}\text { When the possibility of survival is low, we recommend reevaluating the patient's condition and } \\
\text { consulting family members regarding futility. It is also possible to consult the institutional ethics } \\
\text { committee regarding the cessation of ECMO support. }\end{array}$ \\
\hline
\end{tabular}

COVID-19, coronavirus disease 2019; ECMO, extracorporeal membrane oxygenation; $\mathrm{PF}$ ratio, $\mathrm{PaO}_{2} / \mathrm{FiO}_{2}$ ratio; ARDS, acute respiratory distress syndrome; VV, venovenous. 
approach, including a cardiothoracic surgeon. It is recommended that each ECMO center should prepare a referral and retrieval system in consideration of its capacity.

\section{Establishment of criteria for patient selection}

ECMO application may be considered if hypoxia (e.g., PF ratio less than $150 \mathrm{~mm} \mathrm{Hg}$ ) or cardiogenic shock (e.g., hypotension, elevated lactate, and metabolic acidosis) persists after appropriate treatment in COVID-19 patients. If the patient's condition is likely to deteriorate in a hospital without ECMO facilities, it is necessary to consider prompt transfer to an ECMO center.

In patients with ARDS, VV ECMO is recommended if the $\mathrm{PF}$ ratio is less than $50 \mathrm{~mm} \mathrm{Hg}$ for more than 3 hours or less than $80 \mathrm{~mm} \mathrm{Hg}$ for more than 6 hours, based on WHO guidelines. If the patient's condition does not improve even after conventional management with optimal ICU care (e.g., MV, prone positioning), ECMO should be recommended within 5 days from the initiation of invasive MV.

Prompt ECMO application is recommended in patients with advanced cardiogenic shock if appropriate medical treatments fail to yield improvements. If cardiogenic shock develops in a patient undergoing VV ECMO, transition to VA or hybrid ECMO should be considered promptly.

An analysis of the Korean COVID-19 ECMO registry showed that diabetes and MV for more than 7 days were significant risk factors for mortality. We recommend a careful decision on ECMO application in such patients.

\section{Stringent triage and allocation criteria of limited resources in a persistent pandemic era}

If the COVID-19 outbreak continues and the shortage of medical and personnel resources (including ECMO facilities) worsens, we recommend that more strict criteria should be applied for patient selection.

\section{Futility and ethical issues of life-sustaining treatment}

When the possibility of survival is low, particularly in patients with a severe neurological injury, irreversible multiple organ failure, or other conditions rendering them incapable of heart/lung transplantation, we recommend reevaluating the patient's condition and consulting with family members regarding the futility of continuing ECMO. It is also possible to consult the institutional ethics committee regarding the cessation of ECMO support.

\section{Conclusion}

MacLaren et al. [35] recently provided a summarized commentary of essential issues to consider for patients before and after ECMO application. The essential principles that are readily accepted still have some uncertainties (e.g., EOLIA inclusion criteria, prone positioning, full-dose anticoagulation, etc.) concerning ECMO use for patients with COVID-19. It is also necessary to develop additional protocols suitable for COVID-19 ECMO management in Korea, and we believe that it is urgent to make additional recommendations on the following topics. First, age is the most critical risk factor in previously published results [34]. However, in Korea's current situation, it is necessary to evaluate the age group that should be excluded from ECMO candidacy. The median age of patients enrolled in the ELSO COVID-19 dashboard is 49 years old [36], whereas, according to unpublished data from the Korean registry, the mean age of ECMO patients was the over 65 years old. As older age ( $>65$ years) has been considered a relative contraindication for ECMO application in many guidelines (including ELSO), more specific age-related indications are needed, taking into account the specific circumstances in Korea. Second, we should seek more specific evidence of the best time to start ECMO based on other clinical variables, especially previously well-established clinical scoring systems such as Respiratory ECMO Survival Prediction score, the Survival after VA ECMO score, and the Sequential Organ Failure Assessment score. Unfortunately, evidence is lacking regarding the use of a specific scoring system in COVID-19 patients for whom ECMO is being considered. Third, the incidence of pulmonary thromboembolism (PTE) in Korean ECMO patients with COVID19 seems low, but may have been underestimated. Although the number of cases remains limited, the fact that we are experiencing COVID-19 patients with suspected coagulopathy and neurological complications during ECMO runs means that anticoagulation protocols and PTE screening protocols need to be improved sooner rather than later. Fourth, it is necessary to develop a referral and retrieval system suitable for the Korean situation. Analyzing the Korean registry mentioned above, half of the 61 COVID-19 ECMO patients were transferred from other hospitals for various reasons. Surprisingly, many of them had been intubated or even underwent ECMO treatment on the same day of transfer. We suggest that it is urgent to establish a public system related to the nationwide trans- 
port system and guidelines for the referral and retrieval system. Lastly, although ECMO is considered a useful treatment that improves patients' chances of survival with severe COVID-19 infection, an insufficiently detailed analysis of the characteristics of Korean COVID-19 ECMO patients has been presented. We will continue to develop an amended version, with additional content, of these recommendations for the management of COVID-19 ECMO patients.

\section{Conflict of interest}

No potential conflict of interest relevant to this article was reported.

\section{Funding}

This work was supported by a Research Program funded by the Korea Centers for Disease Control and Prevention (2020ER532400).

\section{ORCID}

In Seok Jeong: https://orcid.org/0000-0002-2249-0667

Woong-Han Kim: https://orcid.org/0000-0003-2837-7929

Jong Hyun Baek: https://orcid.org/0000-0001-6430-0035 Chang-Hyu Choi: https://orcid.org/0000-0002-1024-7432

Chang Woo Choi: https://orcid.org/0000-0002-8042-7447 Euy Suk Chung: https://orcid.org/0000-0003-2942-2322 Jae Seok Jang: https://orcid.org/0000-0002-0693-8863 Woo Sung Jang: https://orcid.org/0000-0003-1576-9472 Hanna Jung: https://orcid.org/0000-0002-2070-3980 Jae-Seung Jung: https://orcid.org/0000-0002-8848-4112 Pil Je Kang: https://orcid.org/0000-0002-7587-0911 Dong Jung Kim: https://orcid.org/0000-0003-0332-3430 Do Wan Kim: https://orcid.org/0000-0003-2262-2882 Hyoung Soo Kim: https://orcid.org/0000-0001-6023-0818 Jae Bum Kim: https://orcid.org/0000-0002-8820-9866 Woo-Shik Kim: https://orcid.org/0000-0003-2787-2186 Young Sam Kim: https://orcid.org/0000-0003-4639-9363 Jae Gun Kwak: https://orcid.org/0000-0002-6375-1210 Haeyoung Lee: https://orcid.org/0000-0003-4972-3608 Seok In Lee: https://orcid.org/0000-0002-8538-4511 Jae Woong Lim: https://orcid.org/0000-0003-4512-0236 Se Jin Oh: https://orcid.org/0000-0002-1516-5313 Tak-Hyuck Oh: https://orcid.org/0000-0002-1300-9149 Chun Soo Park: https://orcid.org/0000-0001-8718-8904 Kyoung Min Ryu: https://orcid.org/0000-0001-8461-6010 Man-Shik Shim: https://orcid.org/0000-0002-3151-4464
Joohyung Son: https://orcid.org/0000-0002-9144-5499 Kuk Hui Son: https://orcid.org/0000-0002-0595-5645 Seunghwan Song: https://orcid.org/0000-0002-7492-2097

\section{References}

1. World Health Organization. Coronavirus disease (COVID-19) pandemic [Internet]. Geneva: World Health Organization; 2019 [cited 2020 Dec 31]. Available from: https://www.who.int/emergencies/diseases/novel-coronavirus-2019.

2. Korea Disease Control and Prevention Agency. COVID-19 [Internet]. Cheongju: Korea Disease Control and Prevention Agency; 2020 [cited 2020 Dec 31]. Available from: https://www.kdca.go.kr/.

3. Brodie D, Slutsky AS, Combes A. Extracorporeal life support for adults with respiratory failure and related indications: a review. JAMA 2019;322:557-68.

4. Cho HJ, Ogino MT, Jeong IS, et al. Pediatric intensive care preparedness and ECMO availability in children with COVID-19: an international survey. Perfusion 2020 Dec 19 [Epub]. https://doi.org/10.1177/ 0267659120981810 .

5. Peek GJ, Mugford M, Tiruvoipati R, et al. Efficacy and economic assessment of conventional ventilatory support versus extracorporeal membrane oxygenation for severe adult respiratory failure (CESAR): a multicentre randomised controlled trial. Lancet 2009;374:1351-63.

6. Australia and New Zealand Extracorporeal Membrane Oxygenation (ANZ ECMO) Influenza Investigators, Davies A, Jones D, et al. EXtracorporeal membrane oxygenation for 2009 influenza A(H1N1) acute respiratory distress syndrome. JAMA 2009;302:1888-95.

7. Forrest P, Ratchford J, Burns B, et al. Retrieval of critically ill adults using extracorporeal membrane oxygenation: an Australian experience. Intensive Care Med 2011;37:824-30.

8. Noah MA, Peek GJ, Finney SJ, et al. Referral to an extracorporeal membrane oxygenation center and mortality among patients with severe 2009 influenza A(H1N1). JAMA 2011;306:1659-68.

9. Pappalardo F, Pieri M, Greco T, et al. Predicting mortality risk in patients undergoing venovenous ECMO for ARDS due to influenza $A$ (H1N1) pneumonia: the ECMOnet score. Intensive Care Med 2013; 39:275-81

10. Patroniti N, Zangrillo A, Pappalardo F, et al. The Italian ECMO network experience during the 2009 influenza $A(H 1 N 1)$ pandemic: preparation for severe respiratory emergency outbreaks. Intensive Care Med 2011;37:1447-57.

11. Pham T, Combes A, Roze H, et al. Extracorporeal membrane oxygenation for pandemic influenza A(H1N1)-induced acute respiratory distress syndrome: a cohort study and propensity-matched analysis. Am J Respir Crit Care Med 2013;187:276-85.

12. Weber-Carstens S, Goldmann A, Quintel M, et al. Extracorporeal lung support in H1N1 provoked acute respiratory failure: the experience of the German ARDS Network. Dtsch Arztebl Int 2013;110: 
543-9.

13. Romagnoli S, Peris A, De Gaudio AR, Geppetti P. SARS-CoV-2 and COVID-19: from the bench to the bedside. Physiol Rev 2020;100: 1455-66.

14. Alshahrani MS, Sindi A, Alshamsi F, et al. Extracorporeal membrane oxygenation for severe Middle East respiratory syndrome coronavirus. Ann Intensive Care 2018;8:3.

15. Cho HJ, Heinsar S, Jeong IS, et al. ECMO use in COVID-19: lessons from past respiratory virus outbreaks: a narrative review. Crit Care 2020;24:301.

16. Combes A, Hajage D, Capellier G, et al. Extracorporeal membrane oxygenation for severe acute respiratory distress syndrome. N Engl J Med 2018;378:1965-75.

17. Goligher EC, Tomlinson G, Hajage D, et al. Extracorporeal membrane oxygenation for severe acute respiratory distress syndrome and posterior probability of mortality benefit in a post hoc Bayesian analysis of a randomized clinical trial. JAMA 2018;320:2251-9.

18. Munshi L, Walkey A, Goligher E, Pham T, Uleryk EM, Fan E. Venovenous extracorporeal membrane oxygenation for acute respiratory distress syndrome: a systematic review and meta-analysis. Lancet Respir Med 2019;7:163-72.

19. Combes A, Peek GJ, Hajage D, et al. ECMO for severe ARDS: systematic review and individual patient data meta-analysis. Intensive Care Med 2020;46:2048-57.

20. World Health Organization. Clinical management of severe acute respiratory infection (SARI) when COVID-19 disease is suspected: interim guidance, 13 March 2020 [Internet]. Geneva: World Health Organization; 2020 [cited 2020 Dec 31]. Available from: http://apps. who.int/iris/handle/10665/331446.

21. World Health Organization. Clinical management of COVID-19: interim guidance [Internet]. Geneva: World Health Organization; 2020 [cited 2020 Dec 31]. Available from: http://www.who.int/publications/i/item/clinical-management-of-covid-19.

22. National Institutes of Health. Coronavirus disease 2019 (COVID-19) treatment guidelines [Internet]. Bethesda (MA): National Institutes of Health; 2020 [cited 2020 Dec 31]. Available from: http://www. covid19treatmentguidelines.nih.gov/.

23. Alhazzani W, Moller MH, Arabi YM, et al. Surviving Sepsis Campaign: guidelines on the management of critically ill adults with coronavirus disease 2019 (COVID-19). Crit Care Med 2020;48: e440-69.

24. Bartlett RH, Ogino MT, Brodie D, et al. Initial ELSO guidance docu- ment: ECMO for COVID-19 patients with severe cardiopulmonary failure. ASAIO J 2020;66:472-4.

25. Shekar K, Badulak J, Peek G, et al. Extracorporeal Life Support Organization coronavirus disease 2019 interim guidelines: a consensus document from an international group of interdisciplinary extracorporeal membrane oxygenation providers. ASAIO J 2020;66:707-21.

26. Ferrando C, Suarez-Sipmann F, Mellado-Artigas R, et al. Clinical features, ventilatory management, and outcome of ARDS caused by COVID-19 are similar to other causes of ARDS. Intensive Care Med 2020;46:2200-11.

27. Goligher EC, Ranieri VM, Slutsky AS. Is severe COVID-19 pneumonia a typical or atypical form of ARDS?: and does it matter? Intensive Care Med 2021;47:83-5.

28. Grasselli G, Tonetti T, Protti A, et al. Pathophysiology of COVID-19associated acute respiratory distress syndrome: a multicentre prospective observational study. Lancet Respir Med 2020;8:1201-8.

29. Giustino G, Pinney SP, Lala A, et al. Coronavirus and cardiovascular disease, myocardial injury, and arrhythmia: JACC focus seminar. J Am Coll Cardiol 2020;76:2011-23.

30. Chow JH, Mazzeffi MA, McCurdy MT. Angiotensin II for the treatment of COVID-19-related vasodilatory shock. Anesth Analg 2020; 131:102-5.

31. Kim IC, Kim HA, Park JS, Nam CW. Updates of cardiovascular manifestations in COVID-19: Korean experience to broaden worldwide perspectives. Korean Circ J 2020;50:543-54.

32. Namendys-Silva SA. ECMO for ARDS due to COVID-19. Heart Lung 2020;49:348-9.

33. Henry BM, Lippi G. Poor survival with extracorporeal membrane oxygenation in acute respiratory distress syndrome (ARDS) due to coronavirus disease 2019 (COVID-19): pooled analysis of early reports. J Crit Care 2020;58:27-8.

34. Barbaro RP, MacLaren G, Boonstra PS, et al. Extracorporeal membrane oxygenation support in COVID-19: an international cohort study of the Extracorporeal Life Support Organization registry. Lancet 2020;396:1071-8.

35. MacLaren G, Combes A, Brodie D. What's new in ECMO for COVID-19? Intensive Care Med 2021;47:107-9.

36. Extracorporeal Life Support Organization. COVID-19 cases on ECMO in the ELSO registry [Internet]. Ann Arbor (MI): Extracorporeal Life Support Organization; 2020 [cited 2020 Dec 31]. Available from: http://www.elso.org/Registry/FullCOVID19RegistryDashboard.aspx. 